January 2005

\title{
Cardiogenic shock after dipyridamole administration for myocardial perfusion imaging
}

Fahim H. Jafary

Aga Khan University

Nageeb Basir

Aga Khan University, nageeb.basir@aku.edu

Adnan Amin

Aga Khan University

Nasiruddin Ahmed

Aga Khan University, nasiruddin.ahmed@aku.edu

Follow this and additional works at: https://ecommons.aku.edu/pakistan_fhs_mc_med_cardiol Part of the Cardiology Commons, Critical Care Commons, and the Pulmonology Commons

Recommended Citation

Abstract not provide by Author/Publisher. 


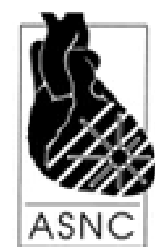

Cover Page

\section{Cardiogenic Shock Following Dipyridamole Administration for Myocardial Perfusion Imaging}

\begin{tabular}{|r|l|}
\hline Journal: & Journal of Nuclear Cardiology \\
\hline Manuscript ID: & JNC-05-005-BU.R1 \\
\hline Manuscript Type: & Bullet \\
\hline Author: & 19-Jan-2005 \\
\hline Complete List of Authors: & $\begin{array}{l}\text { Jafary, Fahim; Aga Khan University Hospital, Section of Cardiology } \\
\text { Basir, Nageeb; Aga Khan University Hospital, Section of Cardiology } \\
\text { Amin, Adnan; Aga Khan University Hospital, Section of Cardiology } \\
\text { Ahmed, Nasiruddin; Aga Khan University Hospital, Section of } \\
\text { Cardiology }\end{array}$ \\
\hline Keywords: & $\begin{array}{l}\text { Vasodilator stress, Unstable angina, Ischemia, myocardial, } \\
\text { Infarction, myocardial, Dipyridamole }\end{array}$ \\
\hline \\
\hline $\begin{array}{l}\text { Note: The following files were submitted by the author for peer review, but cannot be converted } \\
\text { to PDF. You must view these files (e.g. movies) online. }\end{array}$ \\
\hline $\begin{array}{l}\text { Figure3.tif } \\
\text { Figure4.tif }\end{array}$ \\
\hline
\end{tabular}

powered by ScholarOne

\section{Manuscript Central ${ }^{\mathrm{TH}}$}




\title{
Cardiogenic Shock Following Dipyridamole
}

\section{Administration for Myocardial Perfusion Imaging}

\author{
Fahim H. Jafary, M.D., F.A.C.C. ${ }^{1}$, Nageeb Basir ${ }^{2}$, M.D., Adnan Amin ${ }^{3}$, M.D., \\ Nasiruddin Ahmed ${ }^{4}$, M.D. \\ 1,2,3,4 Department of Medicine, \\ Section of Cardiology, \\ Aga Khan University Hospital, Karachi, Pakistan. \\ $\S$ corresponding author
}

Address for Correspondence:

Fahim H. Jafary, M.D., F.A.C.C.

Assistant Professor and Consultant Cardiologist

Department of Medicine, Section of Cardiology

Aga Khan University Hospital

PO Box 3500, Stadium Road, Karachi 74800

Pakistan

Fax $+9221493-4294$

Telephone $+92214859-4700$

Email jafary@pobox.com

Competing Interests: None

Word Count

981 


\section{Case Presentation:}

This 52-year-old gentleman with a prior history of hypertension, transient ischemic attacks and prior myocardial infarction 24-years ago presented to our hospital with a two week history of worsening exertional angina. He was brought to the nuclear laboratory for a dipyridamole myocardial perfusion study. Resting images were taken following the injection of $290 \mathrm{MBq}$ of intravenous Tc-99m tetrofosmin (figure 1). Dipyridamole was infused at $0.56 \mathrm{mg} / \mathrm{kg}$ over four minutes. A few minutes after completion of the infusion the patient's initial blood pressure declined from $120 / 70 \mathrm{~mm} \mathrm{Hg}$ to $70 / 40 \mathrm{~mm} \mathrm{Hg}$. This was associated with profound ST-depression in multiple ECG leads (figure 2), chest pain, dyspnea and overt signs of congestive heart failure. He was given intravenous aminophylline $(125 \mathrm{mg})$ immediately with improvement in his blood pressure to $90 \mathrm{~mm} \mathrm{Hg}$ systolic and partial resolution of the ST depression on his ECG. Owing to his unstable condition, stress images were deferred and the patient was shifted immediately to the cardiac catheterization laboratory where he was electively intubated for worsening heart failure and hypoxemia. Coronary angiography revealed critical left main coronary artery disease (figure 3; single arrow) with poor antegrade flow in the left anterior descending (LAD) artery (figure 3; small arrows) and complete occlusion of the left circumflex (LCX) artery. The right coronary artery also had a critical lesion proximally (figure 4; single arrow) with collateral flow to the LCx (figure 4; double arrows) and the LAD (figure 4; arrowheads). An intra-aortic balloon pump was inserted and the patient was taken for emergent coronary artery bypass surgery. He received vein grafts to the $L A D$, right coronary and marginal arteries. His post-operative course was relatively uneventful and he was discharged on the seventh day after the operation. Creatine-kinase (MB) prior to surgery 
was $30.6 \mathrm{ng} / \mathrm{ml}$ (0-3.97). Left ventricular function following discharge was $40-45 \%$ by echocardiography.

\section{Discussion:}

Intravenous dipyridamole is a widely used agent for pharmacologic stress myocardial perfusion imaging (MPI). Dipyridamole induces a differential degree of coronary vasodilatation in beds supplied by normal and stenosed epicardial coronary arteries. As the vessels subtended by a stenosed coronary artery are significantly dilated at rest, further dilatation (and increase in flow) in response to a vasodilator like dipyridamole is limited. On the other hand, vessels in the normal areas undergo significantly more vasodilation (and increase in flow) leading to heterogeneity of perfusion and, hence, a difference in uptake of flow-dependent radioisotopes likes technetium following dipyridamole administration. Thus, although regions supplied by stenotic epicardial arteries appear "ischemic" on MPI due to differential blood flow (and radiotracer uptake), in the majority of cases true tissue ischemia does not occur - in fact, due to some degree of additional vasodilatation in response to dipyridamole (over the resting state) coronary blood flow actually increases in these underperfused regions ${ }^{1}$.

The exception to this is when the phenomenon of "coronary steal" occurs, whereby an unfavorable redistribution of blood flow takes place from underperfused areas towards better perfused regions 2, 3. This has been described in association with collateral dependent myocardium, which becomes ischemic following coronary vasodilation because of a decrease in pressure in the distal bed of the 
feeder vessel. Perfusion to the collateralized myocardium declines as blood flow takes the path of "least resistance". Estimates suggest that this phenomenon can occur in as many as $45 \%$ of patients with severe coronary artery disease ${ }^{4}$ and is frequently associated with ischemic STsegment depression ${ }^{3}$. There are a number of reports in the literature of severe transient ischemia induced during intravenous ${ }^{5}$ and oral 6,7 dipyridamole administration requiring reversal of the effect with intravenous aminophylline as well as intravenous nitrates. However, the overall incidence is extremely low. In a large series on the adverse effects of dipyridamole MPI published by Ranhosky et al., 8 four out of 3911 patients $(0.10 \%)$ suffered a major adverse cardiac event (two fatal and two nonfatal myocardial infarctions). Three of these four patients had a previous history of worsening angina. More recently, in a report on 73,806 patients who underwent intravenous dipyridamole MPI ${ }^{9}$, there were seven cardiac deaths $(0.95$ per 10,000$)$ and 13 nonfatal myocardial infarctions $(1.76$ per 10,000). Although transient hypotension can occur in approximately $5 \%$ of subjects ${ }^{8}$, to date there are no formal reports of cardiogenic shock precipitated by intravenous dipyridamole. In our patient the left coronary system was essentially occluded and was extensively collateralized by the right coronary artery. While it is possible that dipyridamole induced hypotension may have triggered an ischemic cascade, it is likely that dipyridamole caused a significant degree of "steal" in the left coronary system leading to acute severe ischemia, heart failure and shock. In retrospect, our patient did give a history of significantly worsening angina (including resting symptoms) over the last few weeks but during the initial assessment he underreported his symptoms. Perhaps if the true symptomatology had been known, he may have been scheduled directly for coronary angiography. However, at the time of the test, the patient was not having active symptoms of angina. 
To the best of our knowledge, this is the first report describing cardiogenic shock occurring following intravenous dipyridamole administration. That said, it is likely that at least some of the patients who suffered myocardial infarctions in the reports by Ranhosky ${ }^{8}$ and Lette ${ }^{9}$ also developed cardiogenic shock. Nevertheless, our report highlights an important (and potentially fatal) complication of dipyridamole MPI. Although fatal complications are extremely rare, especially with the advent of aggressive coronary revascularization (Rahnosky's paper ${ }^{8}$, for example, included patients who were tested between 1978 and 1985 when aggressive coronary intervention was not in common practice) it is essential to be cognizant of the possibility and the presence of appropriate backup services is important to prevent catastrophic events. This is of particular relevance to office-based nuclear cardiology facilities. This report also reemphasizes the fact that patients with active unstable angina should not undergo dipyridamole MPI unless stabilized. 
References

1. Gould KL, Casscells SW, Buja LM, Goff DC. Non-invasive management of coronary artery disease. Report of a meeting at the University of Texas Medical School at Houston. Lancet 1995; 346:750-3.

2. Wilcken DE, Paoloni HJ, Eikens E. Evidence for intravenous dipyridamole (persantin) producing a "coronary steal" effect in the ischaemic myocardium. Aust N Z J Med 1971; $1: 8-14$.

3. Chambers CE, Brown KA. Dipyridamole-induced ST segment depression during thallium201 imaging in patients with coronary artery disease: angiographic and hemodynamic determinants. Journal of the American College of Cardiology 1988; 12:37-41.

4. Akinboboye OO, Idris O, Chou RL, Sciacca RR, Cannon PJ, Bergmann SR. Absolute quantitation of coronary steal induced by intravenous dipyridamole. Journal of the American College of Cardiology 2001; 37:109-16.

5. Hansen $\mathrm{CL}$, Williams E. Severe transmural myocardial ischemia after dipyridamole administration implicating coronary steal. Clin Cardiol 1998; 21:293-6.

6. Biddle P, Lanspa TJ, Mohiuddin SM, Malesker MA, Hilleman DE. Myocardial infarction after dipyridamole-assisted thallium-201 imaging. Dicp 1989; 23:665-7.

7. Kwai AH, Jacobson AF, McIntyre KM, Williams WH, Tow DE. Persistent chest pain following oral dipyridamole for thallium 201 myocardial imaging. Eur J Nucl Med 1990; 16:745-6.

8. Ranhosky A, Kempthorne-Rawson J. The safety of intravenous dipyridamole thallium myocardial perfusion imaging. Circulation 1990; 81:1205-1209.

9. Lette J, Tatum JL, Fraser S, et al. Safety of dipyridamole testing in 73,806 patients: the Multicenter Dipyridamole Safety Study. J Nucl Cardiol 1995; 2:3-17. 


\section{Conflicts of Interest: None}

\section{Footer Text}




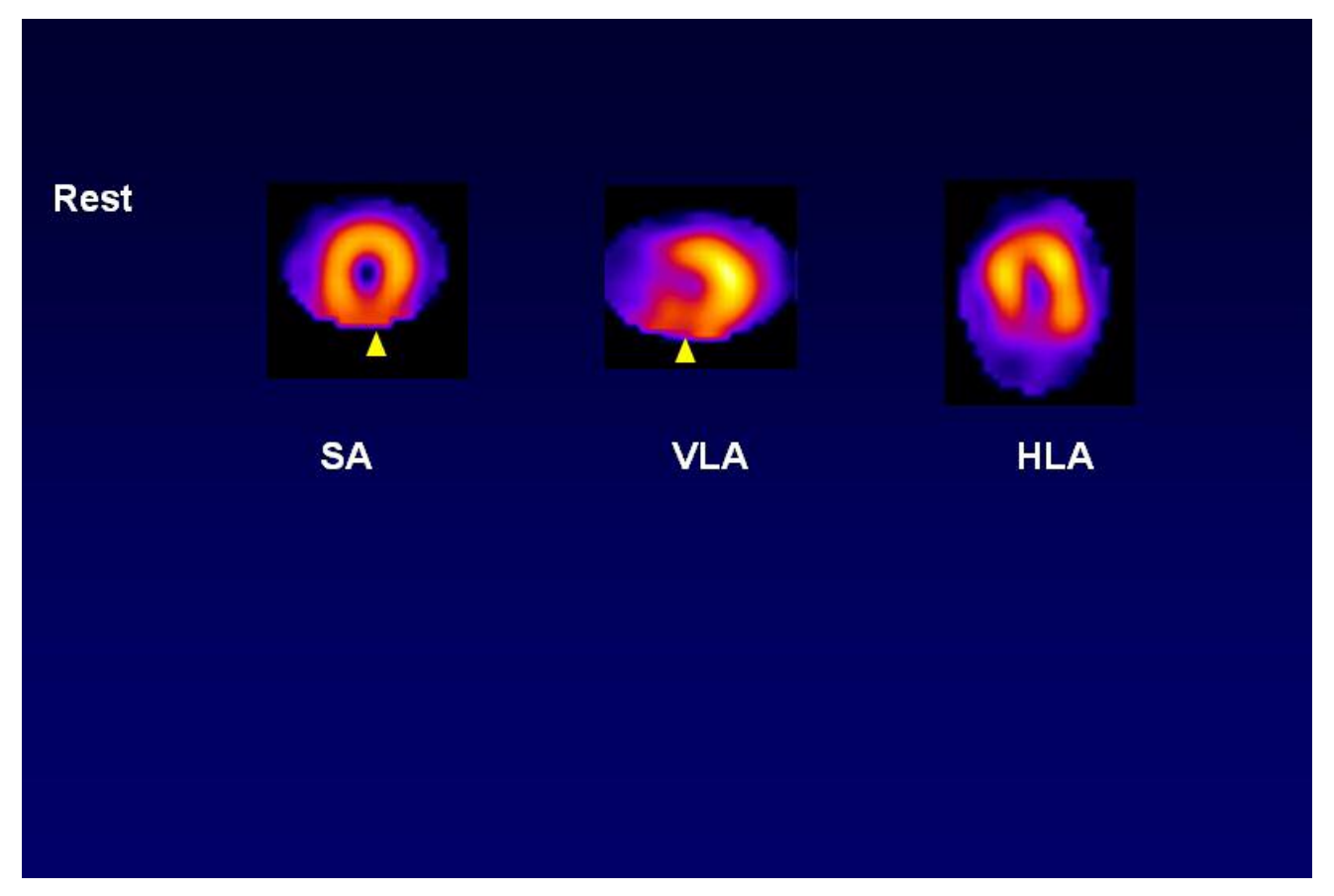

Resting images showing an inferior perfusion defect $285 \times 190 \mathrm{~mm}(72 \times 72 \mathrm{DPI})$ 


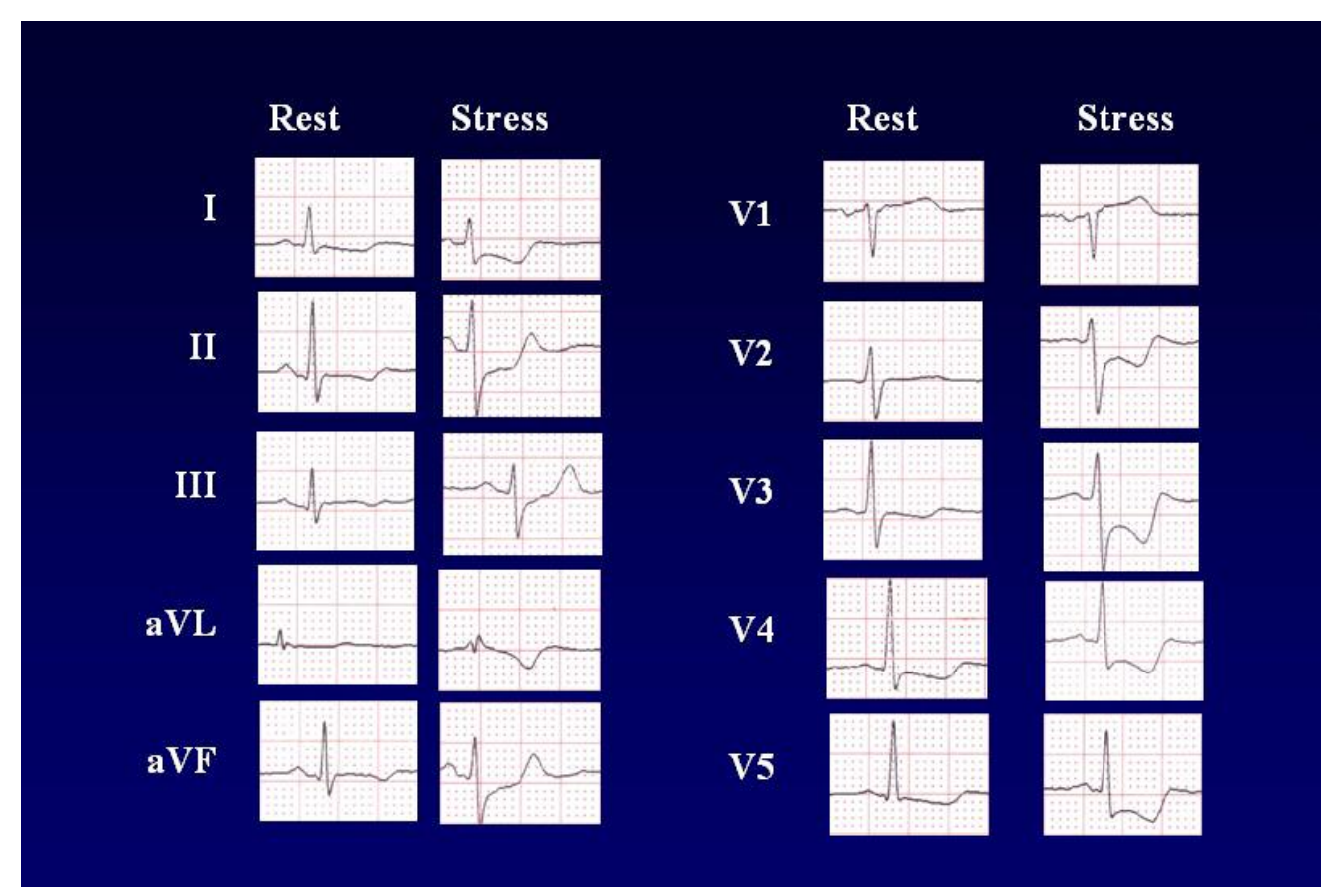

Baseline and Stress ECG

285x190mm (72 x 72 DPI) 